\title{
Inactivation of Cronobacter malonaticus cells and inhibition of its biofilm formation exposed to hydrogen peroxide stress
}

\author{
Yingwang Ye, ${ }^{*} \dagger^{1,2}$ Maofeng Zhang, ${ }^{* 2}$ Rui Jiao, ${ }^{* 2} \mathrm{Na}$ Ling, $\dagger$ Xiyan Zhang, ${ }^{*}$ Liaowang Tong, ${ }^{*}$ Haiyang Zeng, $\dagger$ \\ Jumei Zhang, $†$ and Qingping Wu† ${ }^{1}$ \\ *School of Food Science and Engineering, Hefei University of Technology, Hefei 230009, China \\ †State Key Laboratory of Applied Microbiology Southern China, Guangdong Provincial Key Laboratory of Microbiology Culture Collection \\ and Application, Guangdong Institute of Microbiology, Guangzhou 510070, China
}

\section{ABSTRACT}

Presence of Cronobacter malonaticus in powdered infant formula (PIF) poses a high risk to infant and public health. Cronobacter malonaticus has been widely distributed in food and food processing environments, and the true origin of C. malonaticus in PIF is poorly understood. Control and prevention of C. malonaticus is necessary for achieving microbial safety of PIF. However, little information about decontamination of $C$. malonaticus is available. In this study, effects of hydrogen peroxide on inactivation and morphological changes of $C$. malonaticus cells were determined. Furthermore, inhibitory effects of $\mathrm{H}_{2} \mathrm{O}_{2}$ on biofilm formation in $C$. malonaticus were also performed. Results indicated that $\mathrm{H}_{2} \mathrm{O}_{2}$ could completely inactivate $C$. malonaticus in sterile water with $0.06 \% \mathrm{H}_{2} \mathrm{O}_{2}$ for $25 \mathrm{~min}, 0.08 \%$ $\mathrm{H}_{2} \mathrm{O}_{2}$ for $15 \mathrm{~min}$, and $0.10 \%$ for 10 min, respectively, whereas the survival rates of $C$. malonaticus in tryptic soy broth medium significantly increased with the same treatment time and concentration of $\mathrm{H}_{2} \mathrm{O}_{2}$. In addition, morphological changes of $C$. malonaticus cells, including cell shrinkage, disruption of cells, cell intercession, and leakage of intercellular material in sterile water after $\mathrm{H}_{2} \mathrm{O}_{2}$ treatment, were more predominant than those in tryptic soy broth. Finally, significant reduction in biofilm formation by $\mathrm{H}_{2} \mathrm{O}_{2}$ was found using crystal violet staining, scanning electron microscopy, and confocal laser scanning microscopy detection compared with control samples. This is the first report to determine the effects of $\mathrm{H}_{2} \mathrm{O}_{2}$ on C. malonaticus cells and biofilm formation. The findings provided valuable information for practical application of $\mathrm{H}_{2} \mathrm{O}_{2}$ for decontamination of C. malonaticus in dairy processing.

\footnotetext{
Received July 9, 2017.

Accepted August 21, 2017.

${ }^{1}$ Corresponding authors: yeyw04@mails.gucas.ac.cn and wuqp203@163.com

${ }^{2}$ These authors contributed to the manuscript equally.
}

Key words: hydrogen peroxide, Cronobacter malonaticus, biofilm formation

\section{INTRODUCTION}

Cronobacter species are considered to be occasional food-borne pathogens involved in neonatal meningitis, necrotizing enterocolitis, and sepsis (Beck-Sague et al., 1994; Badger et al., 1999; Blasig et al., 2001), and also isolated from various samples including food-processing plants, food, water, soil, and clinical samples (Gurtler et al., 2005; Ye et al., 2014). Genomic analysis indicated that Cronobacter sakazakii, Cronobacter malonaticus, and Cronobacter turicensis were associated with severe infections (Kucerova et al., 2010). The true origin of C. malonaticus in powdered infant formula is poorly understood, although Cronobacter (formerly known as Enterobacter sakazakii) strains in powdered infant formula might originate from food-processing environments, as described by Mullane et al. (2007).

Cross-contamination or persistent contamination of food-borne pathogens in food samples have been determined to be from bacterial biofilms on surfaces of food engineering plants and equipment (Srey et al., 2013; Cappitelli et al., 2014). In recent years, biofilm-forming abilities on surfaces in Cronobacter strains have been studied (Lee et al., 2012; Jung et al., 2013; Ye et al., 2015), and a capsule biofilm was considered to contribute to survival of Cronobacter strains under environmental stresses (Iversen and Forsythe, 2003). Therefore, controlling food-borne C. malonaticus strains and biofilm formation is extremely important to newborn and public health.

Hydrogen peroxide is a well-studied sanitizer for inactivate food-borne pathogens (Guan et al., 2013; Back et al., 2014) with bacteriostatic and bactericidal activity (Olmez and Kretzschmar, 2009). In addition, hydrogen peroxide is regarded as a safe disinfecting agent due to no harmful residue after treatment, and inactivation of $\mathrm{H}_{2} \mathrm{O}_{2}$ solutions on Escherichia coli O157, Listeria monocytogenes, and Salmonella have been studied (Sapers 
et al., 2000; Huang and Chen, 2011; Choi et al., 2012; Guan et al., 2013; Back et al., 2014; Jiang et al., 2017). However, little work has focused on the effects of hydrogen peroxide on inactivation C. malonaticus cells and inhibition of biofilm formation.

In the present study, the effects of hydrogen peroxide on the survival and morphological injury of C. malonaticus cells were determined using plate counting method and scanning electron microscopy. Furthermore, inhibitory roles of hydrogen peroxide on biofilms formation in C. malonaticus were also performed using crystal violet staining (CVS), scanning electron microscopy, and confocal laser scanning microscopy (CLSM).

\section{MATERIALS AND METHODS}

\section{Strains and Preparation of Hydrogen Peroxide}

Cronobacter malonaticus GDMCC-11 is isolated from aquatic food samples and comes from Guangdong Microbiology Culture Center (GDMCC). Hydrogen peroxide (30\%, Sinopharm Chemical Reagent Co. Ltd., Shanghai, China) were added into sterile tryptic soy broth (TSB; Huankai, Guangzhou, China) for preparation of 0 (control, vol/vol), 0.02, 0.04, 0.06, 0.08, and $0.10 \% \mathrm{H}_{2} \mathrm{O}_{2}$.

\section{Inactivity of C. malonaticus Cells by Hydrogen Peroxide}

Cronobacter malonaticus was inoculated into TSB for incubation at $37^{\circ} \mathrm{C}$ for 14 to $16 \mathrm{~h}$. The C. sakazakii with $10^{6} \mathrm{cfu} / \mathrm{mL}$ was then transferred into sterile water and TSB containing 0 (control, vol/vol), $0.020 .04 \%$, $0.06,0.08$, and $0.10 \% \mathrm{H}_{2} \mathrm{O}_{2}$ for incubation of 10,20 , and $30 \mathrm{~min}$. Finally, the survival of $C$. malonaticus was counted using plating method and each experiment was done in triplicate.

\section{Morphological Changes of C. malonaticus by $\mathrm{H}_{2} \mathrm{O}_{2}$ using Scanning Electron Microscopy}

To determine the morphological changes of $\mathrm{H}_{2} \mathrm{O}_{2}$ treatment, 2 set of experiments were designed. In one set of experiments, C. malonaticus cells were inoculated into sterile TSB at $37^{\circ} \mathrm{C}$, and then the enrichment culture $(100 \mu \mathrm{L}$, optical density $(\mathrm{OD})$ at $600 \mathrm{~nm}=0.5)$ was transferred into $5 \mathrm{~mL}$ of sterile TSB broth or sterile water containing $0,0.02,0.04,0.06,0.08$, and $0.10 \%$ $\mathrm{H}_{2} \mathrm{O}_{2}$ for 15 min of treatment at $37^{\circ} \mathrm{C}$. In another set of experiments, the enrichment culture $(100 \mu \mathrm{L}$, OD at $600 \mathrm{~nm}=0.5$ ) was transferred into $5 \mathrm{~mL}$ of sterile TSB broth or sterile water containing $0.6 \% \mathrm{H}_{2} \mathrm{O}_{2}$ for treatment of about 5, 10, 15, 20, 25, and $30 \mathrm{~min}$. The cultures were then harvested, and pellets cells were used for gradient dehydration with ethanol described by Wang et al. (2013) with little modification. Finally, the treated cells by $\mathrm{H}_{2} \mathrm{O}_{2}$ were subject to scanning electron microscopy analysis (S8020, Hitachi, Tokyo, Japan).

\section{Effects of $\mathrm{H}_{2} \mathrm{O}_{2}$ on Biofilm Formation in C. malonaticus}

For CVS detection, C. malonaticus was inoculated into $5 \mathrm{~mL}$ of TSB and grown for 12 to $14 \mathrm{~h}$ at $37^{\circ} \mathrm{C}$ with constant shaking. Fifty microliters of culture (OD at $600 \mathrm{~nm}=0.5)$ were inoculated into 96 -well polystyrene plates containing $250 \mu \mathrm{L}$ of sterile Luria-Bertani broth with $0,0.02,0.04,0.06,0.08$, and $0.10 \% \mathrm{H}_{2} \mathrm{O}_{2}$, and incubated at $37^{\circ} \mathrm{C}$ for 24,48 , and $72 \mathrm{~h}$. The plates were rinsed 3 times with deionized water, and the adherent

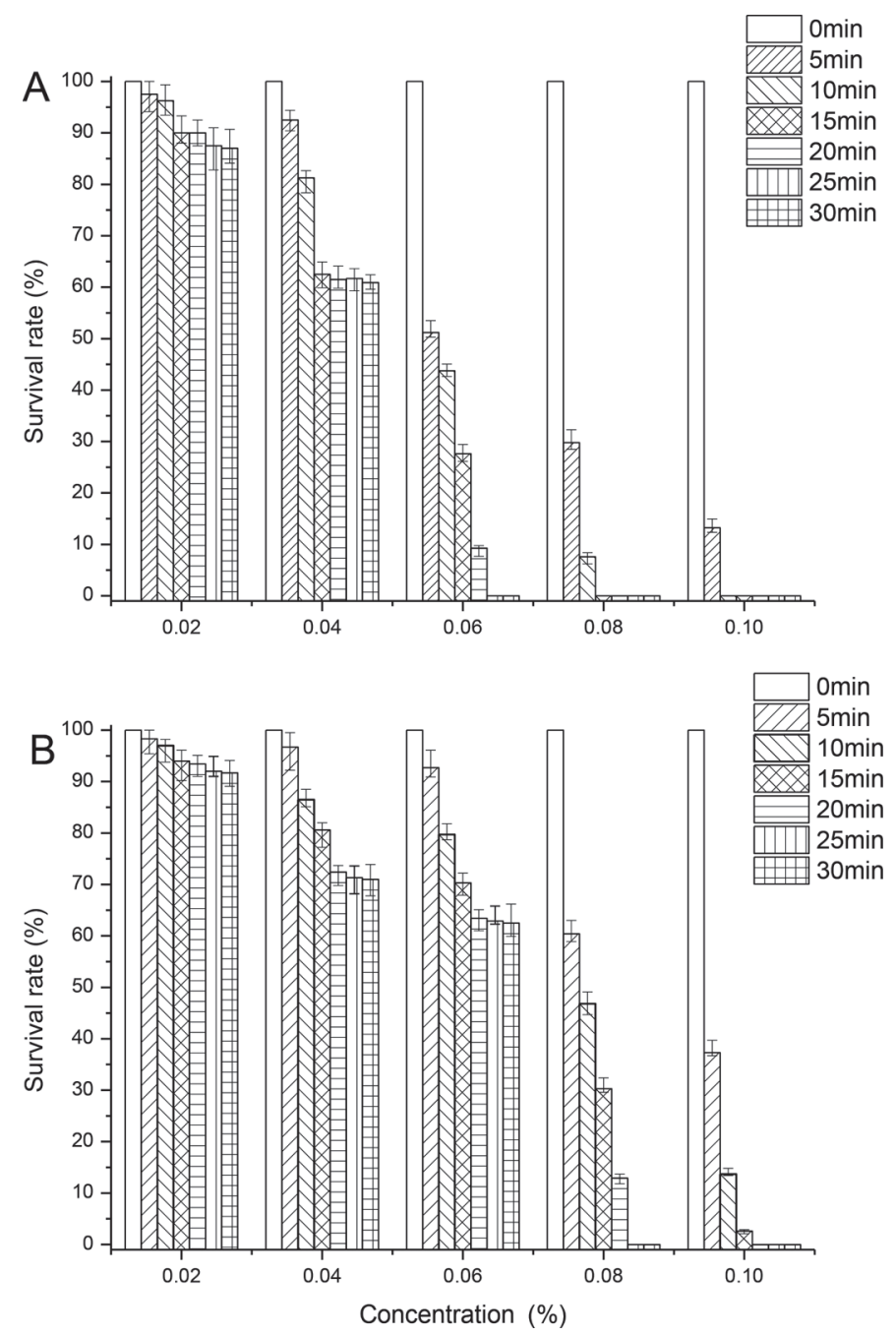

Figure 1. Inactivation of Cronobacter malonaticus cells exposed to hydrogen peroxide with different concentrations in sterile water (A) and tryptic soy broth (TSB) medium (B). Survival rates: means \pm SD. 
bacteria cells were stained with $1 \%$ crystal violet for 30 min. After being rinsed 3 times with deionized water, the crystal violet was liberated by $30 \%$ acetic acid following a 10-min incubation. The OD values of each well were measured at $590 \mathrm{~nm}$.

For biofilm formation detection by scanning electron microscopy, C. malonaticus was inoculated in sterile TSB broth at $37^{\circ} \mathrm{C}$ for 12 to $14 \mathrm{~h}$, and $0.05 \mathrm{~mL}$ of the cultures were transferred to 24-wells plates (Baiyan, Shanghai, China) containing $5 \mathrm{~mL}$ of fresh TSB with 0 (control), 0.02, 0.04, and $0.06 \% \mathrm{H}_{2} \mathrm{O}_{2}$. To test biofilm formation on glass, glass coverslips (Jingan, Shanghai, China) were immersed in TSB broth and then inoculated with $C$. malonaticus. The coverslips were incubated inside 24 -well plates at $37^{\circ} \mathrm{C}$ for 24,48 , and $72 \mathrm{~h}$, after which time bacterial biofilm formation was observed. During this biofilm-formation period, at 24 h-intervals old culture medium was replaced with fresh TSB. The glass coverslips with different incubation times were rinsed in PBS and fixed with $2.5 \%$ glutaraldehyde overnight at $4^{\circ} \mathrm{C}$. Postfixation was carried out using $1 \%$ osmium tetroxide for $2 \mathrm{~h}$ before dehydration in an ethanol series $(50,70,80,90$, and $100 \% ; 30 \mathrm{~min}$ for each concentration). The dehydrated biofilms were coated with a thin layer of gold and examined under a
Hitachi SU1510 scanning electron microscope using an accelerating voltage of $5 \mathrm{kV}$.

To better visualize the biofilm architecture, C. malonaticus was inoculated in TSB at $37^{\circ} \mathrm{C}$ for overnight and $0.05 \mathrm{~mL}$ of the cultures were transferred to 24 -well plates (Baiyan) containing $5 \mathrm{~mL}$ of sterile TSB with 0 (control), 0.02, 0.04, and $0.06 \% \mathrm{H}_{2} \mathrm{O}_{2}$. To test biofilm formation on glass, glass coverslips (Jingan) were immersed in TSB broth and then inoculated with $C$. malonaticus. The coverslips were incubated inside 24well plates at $37^{\circ} \mathrm{C}$ for 24,48 , and $72 \mathrm{~h}$, after which time bacterial biofilm formation on glass slips was stained with LIVE/DEAD BacLight bacterial viability Kit (Invitrogen, Carlsbad, CA) and were subsequently observed by CLSM (Zeiss, Berlin, Germany).

\section{RESULTS AND DISCUSSION}

As one of the important species within the genus of Cronobacter, the control and prevention of C. malonaticus due to cross- or persistent-contamination is important for achieving microbial safety of powdered infant formula. In our study, with increasing amounts of $\mathrm{H}_{2} \mathrm{O}_{2}$ in sterile water, the survival rates of $C$. malonaticus cells significantly decreased $(P<0.01)$, as shown in

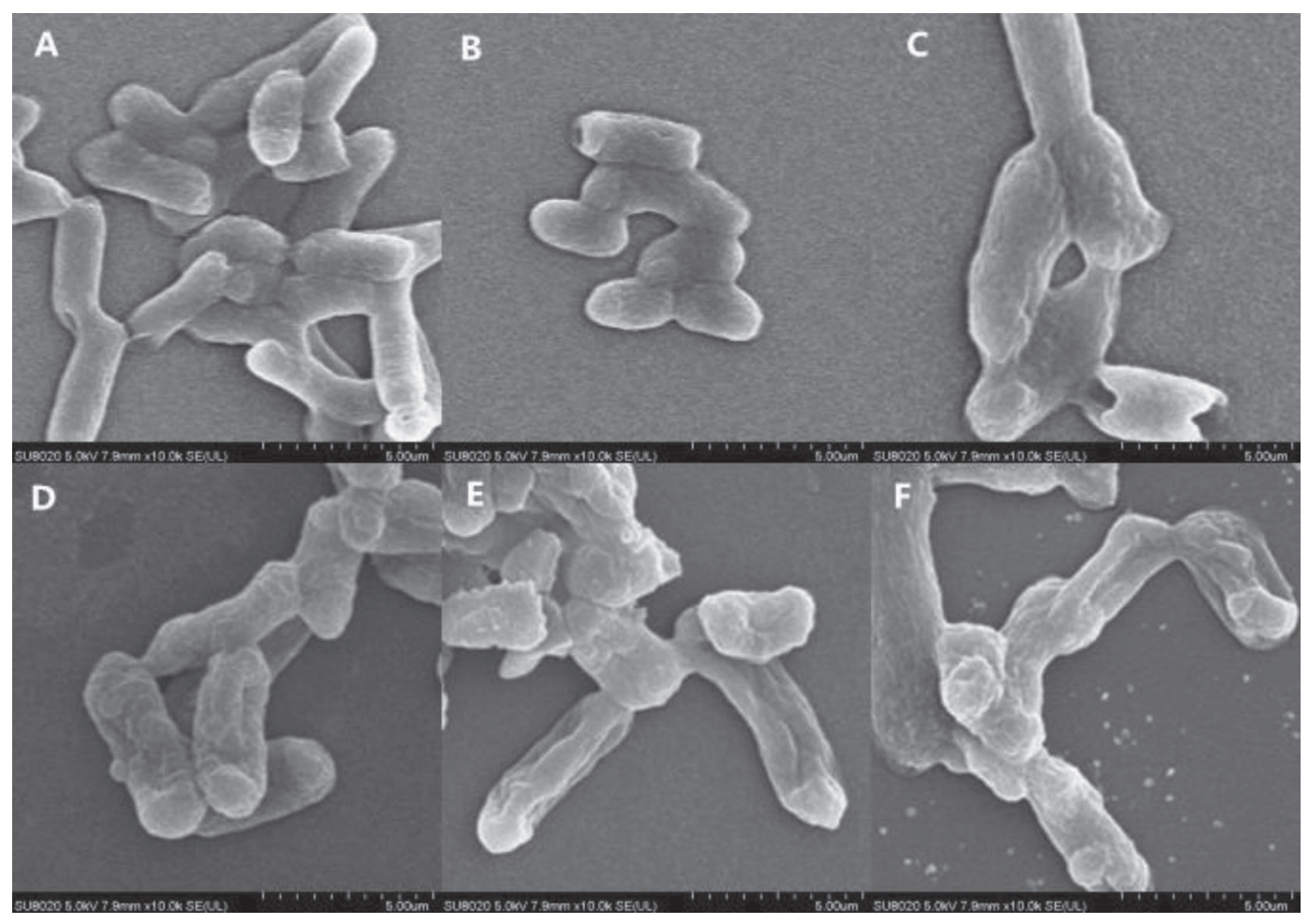

Figure 2. Morphological changes of Cronobacter malonaticus cells exposed to hydrogen peroxide with different concentrations in sterile water for 15 min. $\mathrm{A}=$ Control group $\left(0 \% \mathrm{H}_{2} \mathrm{O}_{2}\right) ; \mathrm{B}=0.02 \% \mathrm{H}_{2} \mathrm{O}_{2} ; \mathrm{C}=0.04 \% \mathrm{H}_{2} \mathrm{O}_{2} ; \mathrm{D}=0.06 \% \mathrm{H}_{2} \mathrm{O}_{2} ; \mathrm{E}=0.08 \% \mathrm{H}_{2} \mathrm{O}_{2} ; \mathrm{F}=0.10 \% \mathrm{H}_{2} \mathrm{O}_{2}$. 


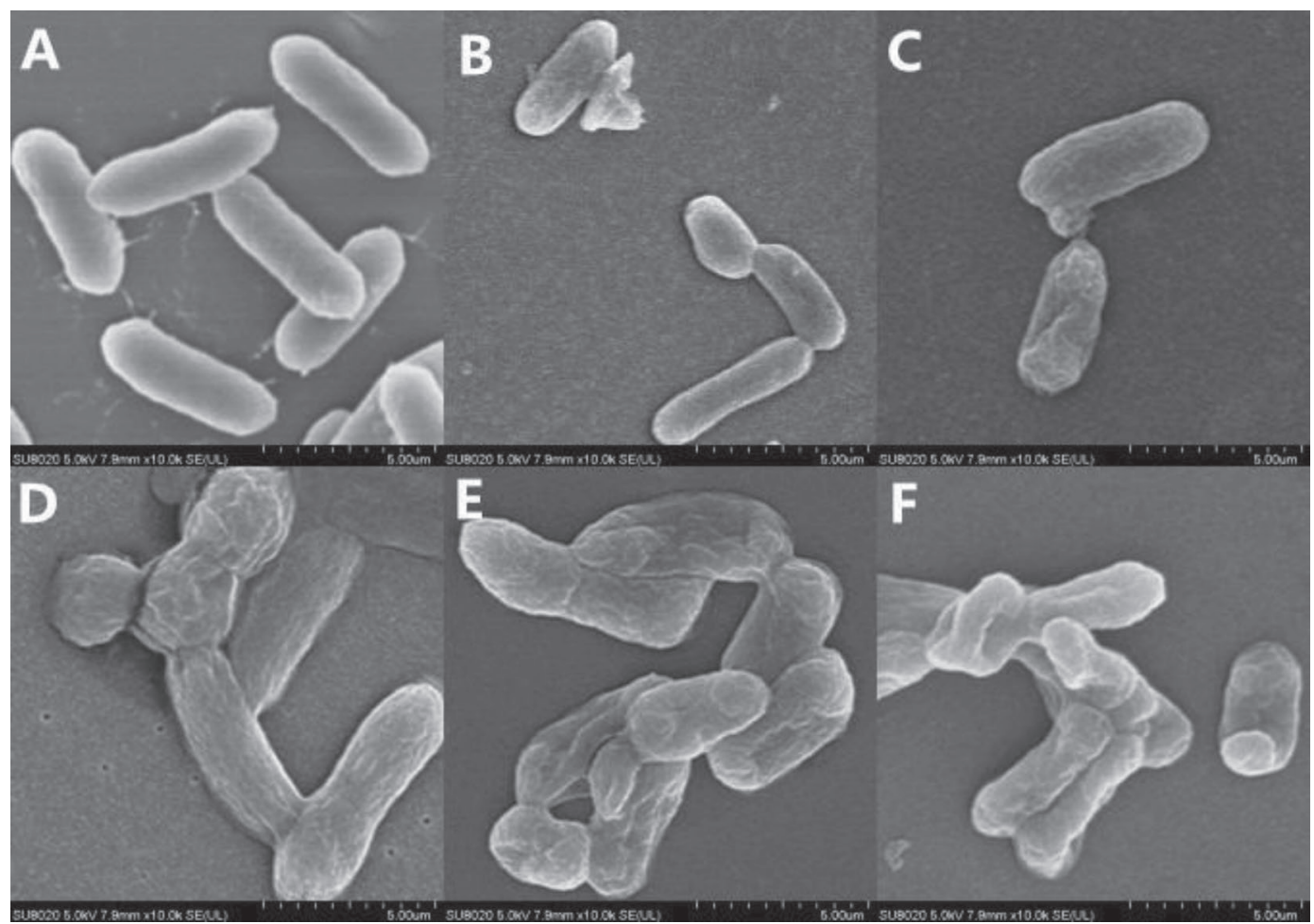

Figure 3. Morphological changes of Cronobacter malonaticus cells exposed to hydrogen peroxide with different concentrations in tryptic soy broth (TSB) medium for 15 min. $\mathrm{A}=$ Control group $\left(0 \% \mathrm{H}_{2} \mathrm{O}_{2}\right) ; \mathrm{B}=0.02 \% \mathrm{H}_{2} \mathrm{O}_{2} ; \mathrm{C}=0.04 \% \mathrm{H}_{2} \mathrm{O}_{2} ; \mathrm{D}=0.06 \% \mathrm{H}_{2} \mathrm{O}_{2} ; \mathrm{E}=0.08 \% \mathrm{H}_{2} \mathrm{O}_{2} ; \mathrm{F}=$ $0.10 \% \mathrm{H}_{2} \mathrm{O}_{2}$.

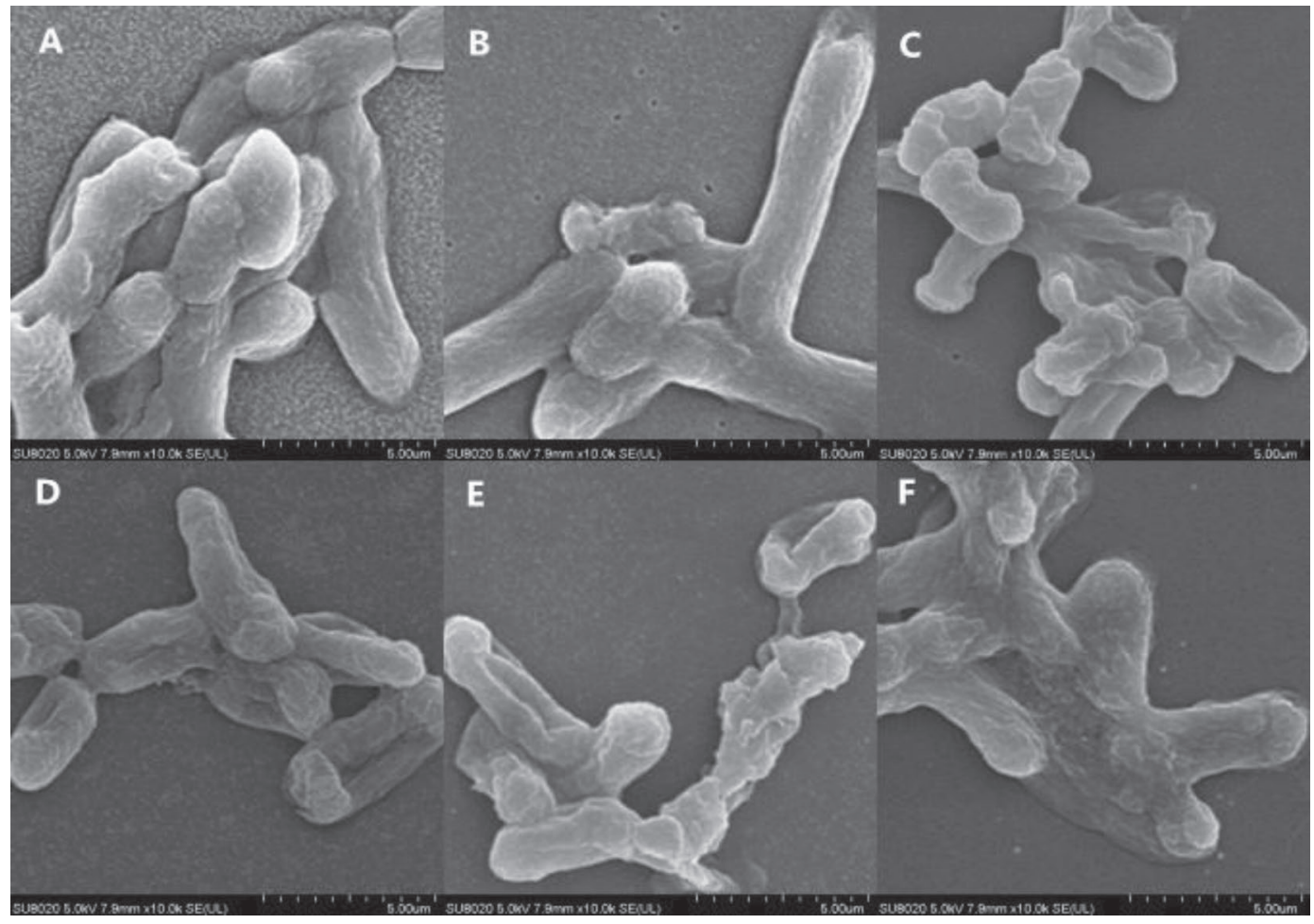

Figure 4. Morphological changes of Cronobacter malonaticus cells exposed to hydrogen peroxide with $0.06 \% \mathrm{H}_{2} \mathrm{O}_{2}$ in sterile water. A $=5$ $\min ; \mathrm{B}=10 \min ; \mathrm{C}=15 \min ; \mathrm{D}=20 \mathrm{~min} ; \mathrm{E}=25 \min ; \mathrm{F}=30 \mathrm{~min}$. 
Figure 1A. In addition, survival rates of C. malonaticus cells in sterile water with 0.02 and $0.04 \% \mathrm{H}_{2} \mathrm{O}_{2}$ after $15 \mathrm{~min}$ of treatment tended to stabilize, and $C$. malonaticus cells were completely killed in sterile water with $0.06,0.08$, and $0.10 \% \mathrm{H}_{2} \mathrm{O}_{2}$ for 25,15 , and 10 min, respectively. In Figure 1B, C. malonaticus in TSB medium was completely inactivated after treatment of $0.08 \% \mathrm{H}_{2} \mathrm{O}_{2}$ for $25 \mathrm{~min}$ and $0.10 \% \mathrm{H}_{2} \mathrm{O}_{2}$ for $20 \mathrm{~min}$. In addition, $\mathrm{H}_{2} \mathrm{O}_{2}$ treatment at $0.06 \%$ could not inactivate C. malonaticus cells within $30 \mathrm{~min}$, suggesting the TSB medium could significantly contribute $(P<0.01)$ to the increasing survival rates of $C$. malonaticus cells under the same concentration of $\mathrm{H}_{2} \mathrm{O}_{2}$ and treatment time. Consequently, nutrients played a protective role on $C$. malonaticus cells under treatment of $\mathrm{H}_{2} \mathrm{O}_{2}$, and organic contents in processing environments should be taken into consideration during control and prevention of $C$. malonaticus.

Aerosolized hydrogen peroxide-based sanitizer were used to reduce the levels of Escherichia coli O157:H7, Listeria monocytogenes, and Salmonella Typhimurium on stainless steel surfaces, and the 3 pathogens were not detected after 60 min with $0.25 \% \mathrm{H}_{2} \mathrm{O}_{2}$ (Choi et al., 2012). Abadias et al. (2011) found that a hydrogen peroxide-based sanitizer at a concentration of $20 \mathrm{~mL} / \mathrm{L}$ for 5 min caused about $4 \log$ reductions of E. coli $\mathrm{O} 157: \mathrm{H} 7$ and Listeria spp. Yeon et al. (2006) demonstrated that an aerosolized hydrogen peroxide-based sanitizer $(1,100$ $\mathrm{mg} / \mathrm{L}$ ) resulted in reductions of 3.5, 3.4, 3.0, and 2.8 $\log \mathrm{cfu} / 100 \mathrm{~cm}^{2}$ of E. coli, Staphylococcus aureus, Salmonella Typhimurium, and L. monocytogenes in or on stainless steel, respectively. The aerosolized hydrogen peroxide-based sanitizer at $22.0 \%$ for $1 \mathrm{~h}$ was effective and resulted in an approximately 5 to $9 \log$ reduction in Salmonella Typhimurium (Lee et al., 2007). Vaporized $10 \%$ hydrogen peroxide treatment for $10 \mathrm{~min}$ decreased levels of Salmonella Typhimurium, E. coli O157:H7, and L. monocytogenes on lettuce by $3.12,3.15$, and 2.95 $\log _{10} \mathrm{cfu} / \mathrm{g}$, respectively (Back et al., 2014). Treatment of lettuce with $2 \% \mathrm{H}_{2} \mathrm{O}_{2}$ at $50^{\circ} \mathrm{C}$ for 2 min decreased Escherichia coli O157:H7 by $4 \log$ (Lin et al., 2002); however, the effects of these sanitizers on inactivation of $E$. coli $\mathrm{O} 157: \mathrm{H} 7$ inoculated onto baby spinach are very limited (Lee and Baek, 2008). Treatment with 3\% $\mathrm{H}_{2} \mathrm{O}_{2}$ and a combination of $\mathrm{H}_{2} \mathrm{O}_{2}$ and UV resulted in 0.77 and $0.87 \mathrm{log} \mathrm{cfu} / \mathrm{g}$ reductions of E. coli O157:H7 inoculated on mushrooms (Guan et al., 2013). Jiang et al. (2017) demonstrated that efficacy of aerosolized hydrogen peroxide depended on type of inoculated bacteria, location of bacteria, and type of produce items, and aerosolized hydrogen peroxide could potentially be used to sanitize fresh fruits and vegetables.

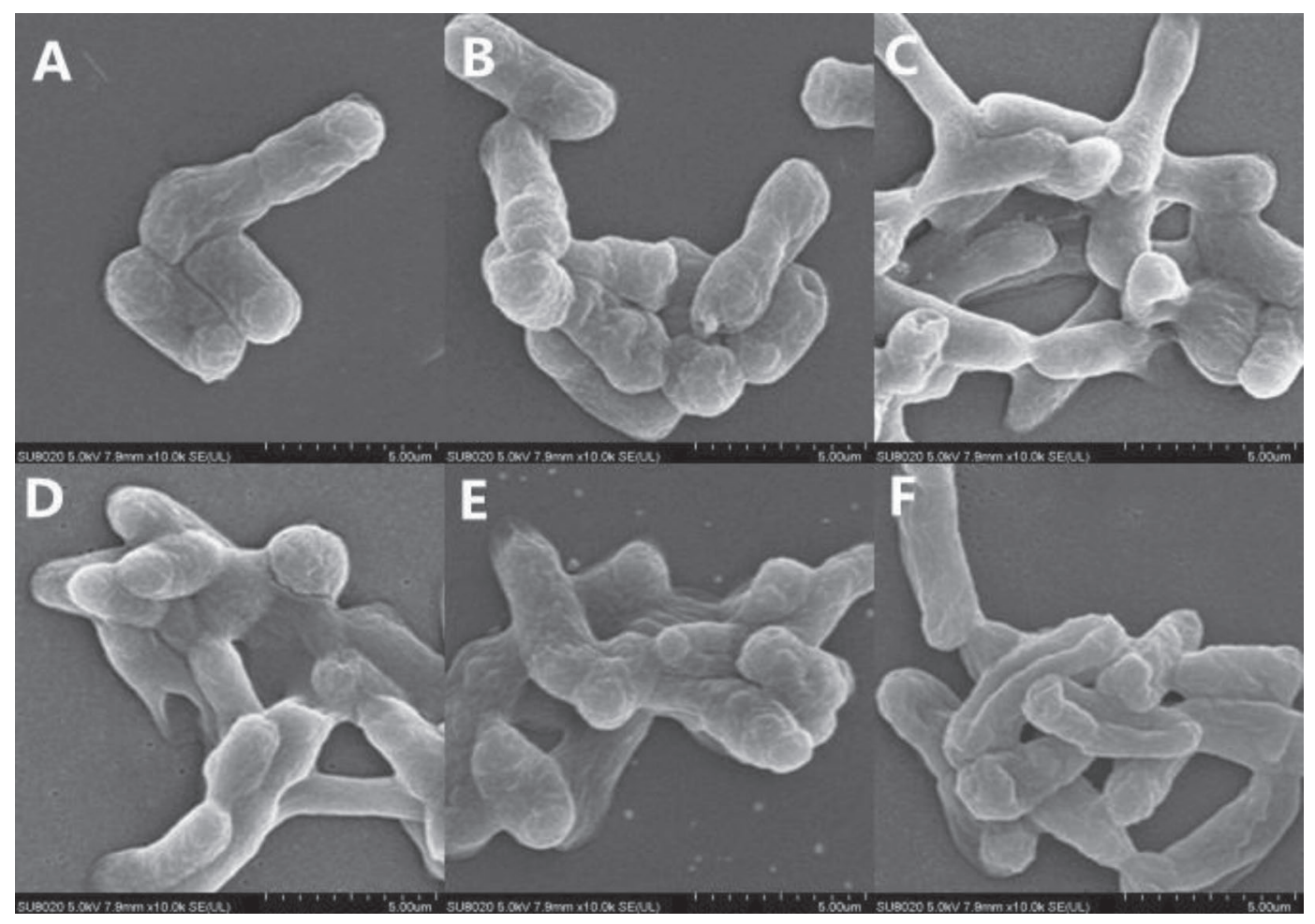

Figure 5. Morphological changes of Cronobacter malonaticus cells exposed to hydrogen peroxide with $0.06 \% \mathrm{H}_{2} \mathrm{O}_{2}$ in tryptic soy broth (TSB) medium. $\mathrm{A}=5 \mathrm{~min} ; \mathrm{B}=10 \mathrm{~min} ; \mathrm{C}=15 \mathrm{~min} ; \mathrm{D}=20 \mathrm{~min} ; \mathrm{E}=25 \mathrm{~min} ; \mathrm{F}=30 \mathrm{~min}$. 

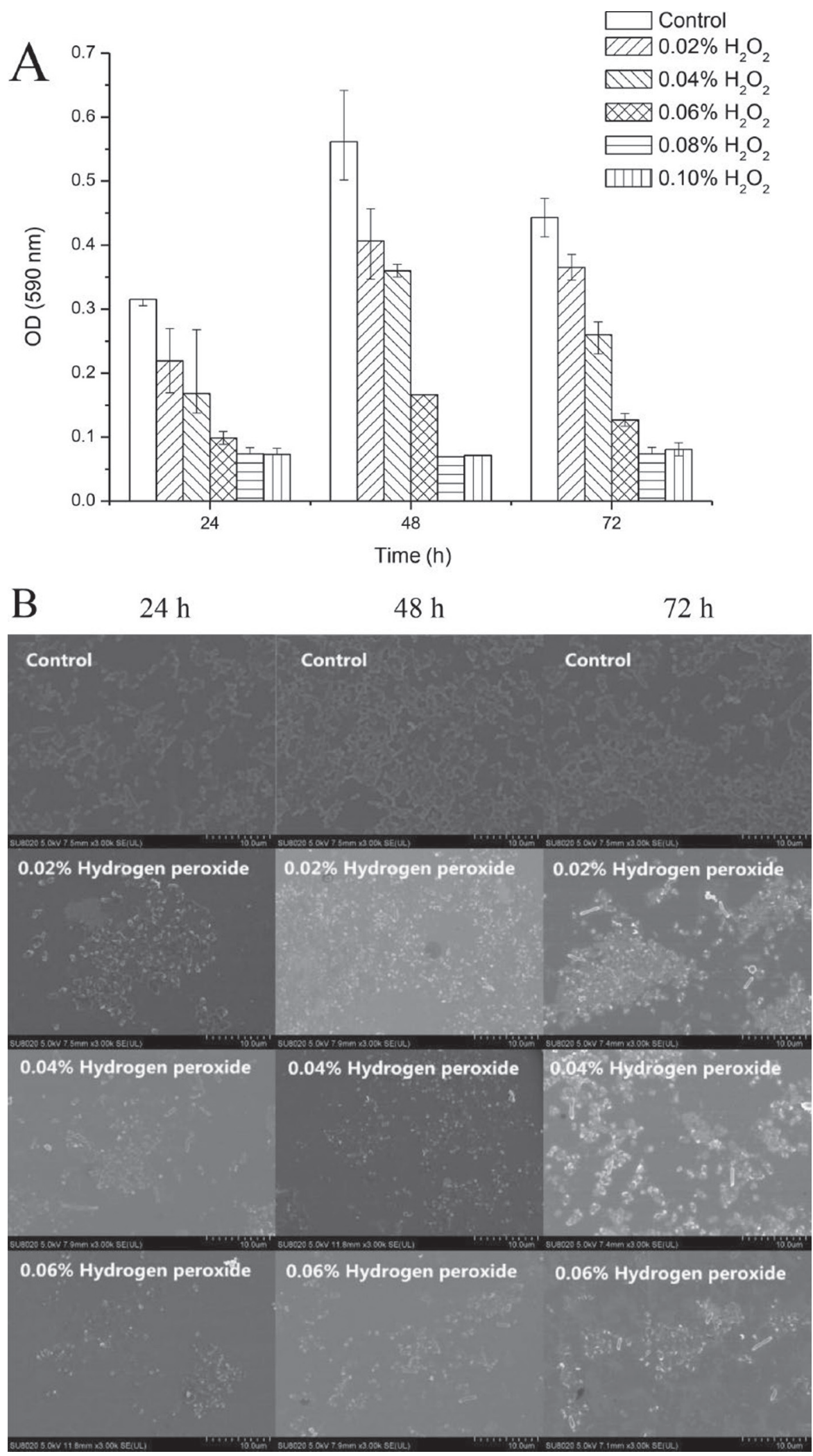

Figure 6. Biofilm formation of Cronobacter malonaticus cells exposed to hydrogen peroxide. A = Quantitative analysis (mean \pm SD) of biofilm formation using crystal violet staining; $\mathrm{OD}=$ optical density. $\mathrm{B}=$ Detection of biofilm formation under different $\mathrm{H}_{2} \mathrm{O}_{2}$ concentrations using scanning electron microscopy. $\mathrm{C}=$ Detection of biofilm formation under different $\mathrm{H}_{2} \mathrm{O}_{2}$ concentrations using confocal laser scanning microscopy. Color version available online. Continued. 


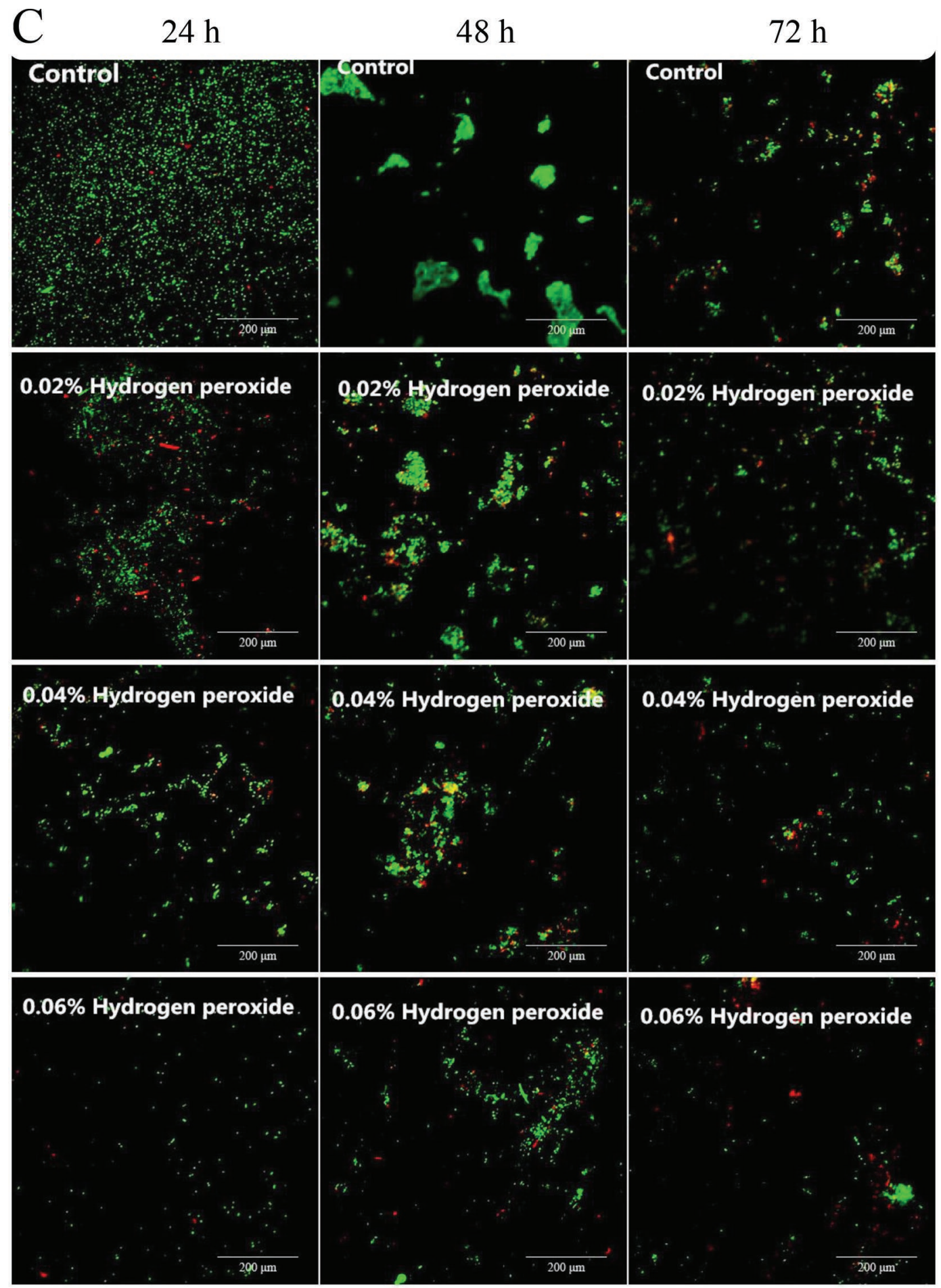

Figure 6 (Continued). Biofilm formation of Cronobacter malonaticus cells exposed to hydrogen peroxide. A = Quantitative analysis (mean $\pm \mathrm{SD}$ ) of biofilm formation using crystal violet staining. $\mathrm{OD}=$ optical density. $\mathrm{B}=$ Detection of biofilm formation under different $\mathrm{H}_{2} \mathrm{O}_{2}$ concentrations using scanning electron microscopy. $\mathrm{C}=$ Detection of biofilm formation under different $\mathrm{H}_{2} \mathrm{O}_{2}$ concentrations using confocal laser scanning microscopy. Color version available online.

From Figure 2, morphological changes of C. malonaticus cells were also observed after treatment of $\mathrm{H}_{2} \mathrm{O}_{2}$ in sterile water. After treatment with 0.02 and $0.04 \%$ Journal of Dairy Science Vol. 101 No. 1, 2018
$\mathrm{H}_{2} \mathrm{O}_{2}$ for 15 min, slight or weak cell shrinkage of $C$. malonaticus was observed, and significant injuries of $C$. malonaticus, including cell shrinkage, disruption of cell, 
and leakage of intracellular material, were observed under treatment with $0.06,0.08$, and $0.10 \% \mathrm{H}_{2} \mathrm{O}_{2}$. After treatment with $\mathrm{H}_{2} \mathrm{O}_{2}$ in TSB medium, injuries of $C$. malonaticus cells were slightly reduced compared with those in sterile water showed in Figure 3. Furthermore, with extension of treatment time by $0.06 \% \mathrm{H}_{2} \mathrm{O}_{2}$ in sterile water (Figure 4) and TSB medium (Figure 5), injuries of $C$. malonaticus, such as cell shrinkage, cell disruption, and cell intercession, clearly increased. In addition, morphological injuries of cells were more predominant than those in TSB medium, which further confirmed protective roles of medium on C. malonaticus cells under $\mathrm{H}_{2} \mathrm{O}_{2}$ stress. In E. coli, exposure to low or high $\mathrm{H}_{2} \mathrm{O}_{2}$ concentrations resulted in morphological changes including cell filamentation, cell volume, and cell membrane damage, followed by loss of intercellular material (Brandi et al., 1989). In contrast, obvious filamentation of $C$. malonaticus cells was not observed using scanning electron microscopy detection in our study.

A hydrogen peroxide-based sanitizer at concentrations of 3 and $5 \%$ for 5 min led to reduction of the viable cells of $>5 \log \mathrm{cfu} / \mathrm{mL}$ on biofilms of Staphylococcus epidermidis (Presterl et al., 2007). The attachment of food-borne pathogens to biotic and abiotic surfaces, followed by biofilm formation, might be the critical factor for persistent-contamination of microorganism in food samples (Choi et al., 2012). In our study, the inhibitory effects of $\mathrm{H}_{2} \mathrm{O}_{2}$ on biofilm formation in C. malonaticus were studied for the first time. The highest biomass in C. malonaticus was formed after $48 \mathrm{~h}$ of incubation at $37^{\circ} \mathrm{C}$ by CVS in Figure $6 \mathrm{~A}$. The biofilm formation was significantly decreased with increasing concentration of $\mathrm{H}_{2} \mathrm{O}_{2}$ in medium, and we noted significant inhibition of biofilm formation of C. malonaticus in TSB containing $0.02,0.04$, and $0.06 \% \mathrm{H}_{2} \mathrm{O}_{2}$ compared with control samples by the CVS method. In addition, C. malonaticus could hardly form biofilms in the TSB containing 0.08 and $0.10 \% \mathrm{H}_{2} \mathrm{O}_{2}$.

Furthermore, biofilm formation of $C$. malonaticus in TSB medium with $0,0.02,0.04$, and $0.06 \% \mathrm{H}_{2} \mathrm{O}_{2}$ was detected using scanning electron microscopy in Figure 6B. We found that biofilm formation of $C$. malonaticus was significantly inhibited with increasing concentrations of $\mathrm{H}_{2} \mathrm{O}_{2}$, and incompact biofilms were observed in TSB medium with $0.06 \% \mathrm{H}_{2} \mathrm{O}_{2}$. To date, little research has focused on control of biofilm formation in C. malonaticus. Our previous study indicated that D-Tryptophan significantly inhibits formation of mature biofilm of $C$. malonaticus and contributes to disassembly of existing biofilms ( $\mathrm{Li}$ et al., 2015). After $72 \mathrm{~h}$ of incubation time, the percentage of dead cells (red or yellow) increased in all samples using CLSM detection. From Figure 6C, compared with control group, the amount of viable cells and dead or injured cells increased. In addition, incompact structure of biofilm after treatment of $\mathrm{H}_{2} \mathrm{O}_{2}$ was also confirmed by CLSM; however, $0.06 \% \mathrm{H}_{2} \mathrm{O}_{2}$ could not completely inhibit the biofilm formation and inactivate $C$. malonaticus cell in TSB medium, suggesting a combination of 2 or more sanitizers is required for removal of C. malonaticus strain and biofilms.

In summary, treatment of hydrogen peroxide with 0.08 and $0.10 \% \mathrm{H}_{2} \mathrm{O}_{2}$ in sterile water and TSB within 25 min could completely inactivate $C$. malonaticus cells. In addition, medium played a protective role for C. malonaticus cells under $\mathrm{H}_{2} \mathrm{O}_{2}$ stress. With the increasing of $\mathrm{H}_{2} \mathrm{O}_{2}$ concentrations and treatment time, injuries of $C$. malonaticus cells were more predominant compared with the control groups. Furthermore, significant inhibition of biofilm formation in C. malonaticus by hydrogen peroxide was observed compared with the control groups for the first time. In addition, inhibitory effects of hydrogen peroxide on biofilm formation were also confirmed through detection of structural changes by scanning electron microscopy and CLSM. To achieve microbial safety of powdered infant formula from contamination with C. malonaticus, a combination of 2 or more sanitizers is recommended.

\section{ACKNOWLEDGMENTS}

We gratefully acknowledge the financial support of the National Natural Science Foundation of China (31671951), the Anhui provincial Grand Project special of Science and Technology (15czz03109), Science and Technology Planning Project of Guangdong Province China (2016A050502033) Project of Science and Technology of Guangzhou, Guangdong Province, China (201604020036), and State Key Laboratory of Applied Microbiology Southern China Open Foundations, Guangzhou, China (SKLAM004-2015).

\section{REFERENCES}

Abadias, M., I. Alegre, J. Usall, R. Torres, and I. Vinas. 2011. Evaluation of alternative sanitizers to chlorine disinfection for reducing foodborne pathogens in fresh cut apple. Postharvest Biol. Technol. 59:289-297.

Back, K. H., J. W. Ha, and D. H. Kang. 2014. Effect of hydrogen peroxide vapor treatment for inactivating Salmonella Typhimurium, Escherichia coli O157:H7 and Listeria monocytogenes on organic fresh lettuce. Food Contr. 44:78-85.

Badger, J. L., M. F. Stins, and K. S. Kim. 1999. Citrobacter freundii invades and replicates in human brain microvascular endothelial cells. Infect. Immun. 67:4208-4215.

Beck-Sague, C. M., P. Azimi, S. Fonseca, R. Baltimore, D. Powell, L. Bland, M. Ardino, S. McAllister, R. Huberman, and R. Sinkowitz. 1994. Bloodstream infections in neonatal intensive care unit patients: Results of a multicenter study. Pediatr. Infect. Dis. J. 13:1110-1116.

Blasig, I. E., H. Giese, M. L. Schroeter, A. Sporbert, D. I. Utepbergenov, I. B. Buchwalow, K. Neubert, G. Schonfelder, D. Freyer, 
I. Schimke, W. E. Siems, M. Paul, R. F. Haseloff, and R. Blasig. 2001. NO and oxyradical metabolism in new cell lines of rat brain capillary endothelial cells forming the blood-brain barrier. Microvasc. Res. 62:114-127.

Brandi, G., M. Fiorani, C. Pierotti, A. Albano, F. Cattabeni, and O. Cantoni. 1989. Morphological changes in Escherichia coli cells exposed to low or high concentrations of hydrogen peroxide. Microbiol. Immunol. 33:991-1000.

Cappitelli, F., A. Polo, and F. Villa. 2014. Biofilm formation in food processing environments is still poorly understood and controlled. Food Eng. Rev. 6:29-42.

Choi, N. Y., S. Y. Baek, J. H. Yoon, M. R. Choi, D. H. Kang, and S. Y. Lee. 2012. Efficacy of aerosolized hydrogen peroxide-based sanitizer on the reduction of pathogenic bacteria on a stainless steel surface. Food Contr. 27:57-63.

Guan, W., X. Fan, and R. Yan. 2013. Effect of combination of ultraviolet light and hydrogen peroxide on inactivation of Escherichia coli $\mathrm{O} 157: \mathrm{H7}$, native microbial loads, and quality of button mushrooms. Food Contr. 34:554-559.

Gurtler, J. B., J. L. Kornacki, and L. R. Beuchat. 2005. Enterobacter sakazakii: A coliform of increased concern to infant health. Int. J. Food Microbiol. 104:1-34.

Huang, Y., and H. Chen. 2011. Effect of organic acids, hydrogen peroxide and mild heat on inactivation of Escherichia coli O157: H7 on baby spinach. Food Contr. 22:1178-1183.

Iversen, C., and S. Forsythe. 2003. Risk profile of Enterobacter sakazakii, an emergent pathogen associated with infant milk formula. Trends Food Sci. Technol. 14:443-454.

Jiang, Y., K. Sokorai, G. Pyrgiotakis, P. Demokritou, X. H. Li, S. Mukhopadhyay, T. Jin, and X. T. Fan. 2017. Cold plasma-activated hydrogen peroxide aerosol inactivates Escherichia coli O157:H7, Salmonella Typhimurium, and Listeria innocua and maintains quality of grape tomato, spinach and cantaloupe. Int. J. Food Microbiol. 249:53-60.

Jung, J.-H., N.-Y. Choi, and S.-Y. Lee. 2013. Biofilm formation and exopolysaccharide (EPS) production by Cronobacter sakazakii depending on environmental conditions. Food Microbiol. 34:70-80.

Kucerova, E., S. W. Clifon, X. Q. Xia, F. Long, S. Porwollik, L. Fulton, C. Fronick, P. Minx, K. Kyung, W. Warren, R. Fulton, D. Feng, A. Wollam, N. Shah, V. Bhonagiri, W. E. Nash, K. Hallwworth-Pepin, R. K. Wilson, M. McClelland, and S. J. Forsythe. 2010. Genome sequence of Cronobacter sakazakii BAA-894 and comparative genomic hybridization analysis with other Cronobacter species. PLoS One 5:e9556.

Lee, S. Y., and S. Y. Baek. 2008. Effect of chemical sanitizer combined with modified atmosphere packaging on inhibiting Escherichia coli O157:H7 in commercial spinach. Food Microbiol. 25:582-587.

Lee, S. Y., J. H. Jung, H. H. Jin, Y. H. Kim, and S. W. Oh. 2007. Inhibitory effect of aerosolized commercial sanitizers against foodborne pathogens. J. Food Hygiene Saf. 22:235-242.
Lee, Y.-D., J.-H. Park, and H. Chang. 2012. Detection, antibiotic susceptibility and biofilm formation of Cronobacter spp. from various foods in Korea. Food Contr. 24:225-230.

Li, H., Y. W. Ye, N. Ling, Q. P. Wu, and J. M. Zhang. 2015. Inhibitory effects of D-tryptophan on biofilm development by the foodborne Cronobacter sakazakii. Int. Dairy J. 49:125-129.

Lin, C. M., S. S. Moon, M. P. Doyle, and K. M. McWatters. 2002. Inactivation of Escherichia coli O157:H7, Salmonella enterica serotype Enteritidis, and Listeria monocytogenes on lettuce by hydrogen peroxide and lactic acid and by hydrogen peroxide with mild heat. J. Food Prot. 65:1215-1220.

Mullane, N. R., P. Whyte, P. G. Wall, T. Quinn, and S. Fanning. 2007. Application of pulsed-field gel electrophoresis to characterize and trace the prevalence of Enterobacter sakazakii in an infant formula processing facility. Int. J. Food Microbiol. 116:73-81.

Olmez, H., and U. Kretzschmar. 2009. Potential alternative disinfection methods for organic fresh-cut industry for minimizing water consumption and environmental impact. LWT Food Sci. Technol. 42:686-693.

Presterl, E., M. Suchomel, M. Eder, S. Reichmann, A. Lassnigg, W. Graninger, and M. Rotter. 2007. Effects of alcohols, povidoneiodine and hydrogen peroxide on biofilms of Staphylococcus epidermidis. J. Antimicrob. Chemother. 60:417-420.

Sapers, G. M., R. L. Miller, M. Jantschke, and A. M. Mattrazzo. 2000 Factors limiting the efficacy of hydrogen peroxide washes for decontamination of apples containing Escherichia coli. J. Food Sci 65:529-532.

Srey, S., I. K. Jahid, and S.-D. Ha. 2013. Biofilm formation in food industries: A food safety concern. Food Contr. 31:572-585.

Wang, C. Y., C. P. Hsu, H. W. Huang, and B. B. Yang. 2013. The relationship between inactivation and morphological damage of Salmonella enterica treated by high hydrostatic pressure. Food Res. Int. 54:1482-1487.

Ye, Y. W., H. Li, Q. P. Wu, J. M. Zhang, and Y. D. Lu. 2014. The Cronobacter sp. in milk and dairy products: Detection and typing. Int. J. Dairy Technol. 67:167-175.

Ye, Y. W., N. Ling, R. Jiao, Q. P. Wu, Y. J. Han, and J. N. Gao. 2015. Effects of culture conditions on the biofilm formation of Cronobacter sakazakii strains and distribution of genes involved in biofilm formation. LWT Food Sci. Technol. 62:1-6.

Yeon, J. H., I. J. Kim, K. H. Park, B. K. Park, H. K. Park, D. W Park, Y. S. Kim, H. I. Kim, D. H. Jeon, Y. J. Lee, and S. D Ha. 2006. Treatment and effect of sanitizers and disinfections in animal food manufacturing plant. Korean J. Food Sci. Technol. 38:599-603. 